Nunt. Antiquus, Belo Horizonte, v. 15, n. 2, p. 145-157, 2019

\title{
Cícero, Do orador 3.213-230
}

\section{Cicero, On the orator 3.213-230}

\author{
Adriano Scatolin \\ Universidade de São Paulo (USP), São Paulo, São Paulo / Brasil \\ adrscatolin@gmail.com
}

Resumo: O passo traduzido divide-se em duas seções: 3.213-227 constitui o tratamento da actio oratória; 3.228-230 é o encerramento do diálogo. A primeira seção subdividese em 1) observações gerais (3.213-219) e o tratamento: 2) da gesticulação (3.220); 3) da fisionomia (3.220-223); e 4) da voz (3.224-227). A segunda seção apresenta as observações finais do protagonista Crasso, com a célebre alusão, no elogio de Hortênsio, ao final do Fedro platônico.

Palavras-chave: Cícero; retórica latina; De oratore; actio.

Abstract: The passage selected is divided into two sections: 3.213-227 constitutes the treatment of oratorical actio; $3.228-230$ presents the closing of the dialogue. The first section is subdivided into 1) general remarks (3.213-219) and the treatment of 2) gestures (3.220); 3) physiongnomy (3.220-223); and 4) voice. The second section presents the final remarks by the protagonist Crassus, with the famous allusion to Plato's Phaedrus in the praise of Hortensius.

Keywords: Cicero; Latin rhetoric; De oratore; actio.

\footnotetext{
${ }^{1}$ Texto de base para a tradução: Kumaniecki (1969). Todas as datas referidas nas notas são a.C. A convenção das abreviações das obras antigas é a do Oxford Latin Dictionary e, no caso do próprio De oratore, usamos apenas a notação de livro e seção. As traduções apresentadas nas notas são nossas, salvo observação em contrário. $\mathrm{O}$ tradutor agradece Marlene Lessa Vergílio Borges pela revisão cuidadosa de sempre.
} 


\section{Critérios de tradução}

$\mathrm{Na}$ tradução, adotamos o decoro como critério norteador de nossos princípios. Assim, o que determinou nossas escolhas foi, antes de tudo, a adequação ao gênero em que o diálogo se insere, justamente o sermo ("conversa" ou "diálogo"). A partir disso, optamos por uma linguagem não elevada - bastante diversa da que estamos acostumados a ver, por exemplo, nas passagens mais patéticas da obra oratória do Arpinate -, embora não rasteira. Fizemos uso do "você(s)" em lugar dos pronomes de segunda pessoa, "tu" e "vós", mais formais, ${ }^{2}$ à exceção apenas dos prólogos dos três livros e, como se poderá observar no passo ora traduzido, nas citações poéticas feitas pelas personagens, em ambos os casos por sua maior elevação elocutiva. Muitas vezes empregamos a locução do verbo "ser" seguido de gerúndio para traduzir o presente latino, em vez do simples presente em português. Não fugimos dos anacolutos, quando nos soavam possíveis e adequados. Usamos regências menos formais em determinados verbos e preferimos muitas vezes a próclise à ênclise, além de descartarmos o uso da mesóclise. Essas e outras táticas (não temos pretensão de exaustividade, e preferimos, ao mesmo tempo, que o leitor possa descobrir por conta própria nosso modus interpretandi) foram empregadas num desejo de tornar o texto o mais natural possível dentro do gênero dialógico, que imita a conversa cotidiana, embora seja, naturalmente, mais elevado do que esta. Cabe ao leitor decidir sobre o êxito de nossos esforços.

\footnotetext{
${ }^{2}$ Desnecessário dizer que a observação não vale para o uso lusitano dos pronomes, ou mesmo para o de diversas regiões do Brasil.
} 


\section{Tradução}

213. Mas tudo isso ${ }^{3}$ depende da atuação do orador. A atuação, insisto, reina sozinha na oratória. ${ }^{4}$ Sem ela, o melhor orador pode não valer nada, um orador menor, munido dela, muitas vezes supera os melhores. ${ }^{5}$ Conta-se que Demóstenes, quando lhe perguntaram qual o elemento mais importante na oratória, concedeu a ela o primeiro, o segundo e o terceiro lugares. ${ }^{6}$ Costumo considerar que o que Ésquines disse é ainda melhor do que isso. Conta-se que, depois que ele deixara Atenas e se dirigira a Rodes, em virtude da ignomínia pela perda de um

\footnotetext{
${ }^{3}$ Crasso refere-se ao tratamento da elocução, que acaba de concluir. Em outros termos, o bom uso do ornato do discurso está intimamente atrelado à boa atuação do orador.

${ }^{4}$ Em 1.60, Crasso usara o mesmo verbo, dominor (traduzido aqui por "reina"), para se referir à importância do uso das emoções no discurso: "[sc. eu me pergunto] se é possível empregar o discurso para inflamar ou mesmo apaziguar os sentimentos e emoções, por excelência o fator de maior importância num orador, sem uma investigação extremamente cuidadosa e completa de todas as doutrinas desenvolvidas pelos filósofos acerca da natureza e do caráter do gênero humano" (Grifo nosso). Não há contradição, dada a íntima ligação da actio com os motus animi. Já Aristóteles, em sua

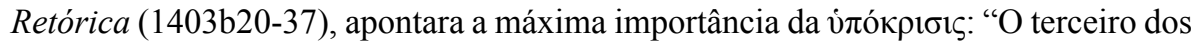
pontos, que detém a maior importância e que ainda não foi tratado, será o dos aspectos respeitantes à pronunciação" (Tradução de Alexandre Junior et al. 2005; referência em Wisse, Winterbottom e Fantham (2008, p. 344)).

${ }^{5}$ Quintiliano parafraseia esta observação, fazendo uso das mesmas anedotas sobre Demóstenes citadas por Crasso e complementando-as a partir de outra(s) fonte(s), em 11.3.5-6: "Realmente, poderia afirmar que mesmo um discurso mediano, prestigiado pelo poder da atuação, tem mais eficácia do que um discurso excelente desprovido dela, se é verdade que também Demóstenes, quando lhe perguntaram o que era mais importante na tarefa de discursar, concedeu ao proferimento o primeiro lugar, bem como o segundo e o terceiro, até que parassem de lhe perguntar, podendo-se depreender que o considerava não o principal fator, mas o único (foi por isso que estudou com tanta dedicação com o ator Andronico, de modo que não parece ter sido sem motivo que Ésquines, em Rodes, teria observado aos admiradores do discurso: 'imaginem se tivessem ouvido o próprio...')".

${ }^{6}$ Cavarzere (2011, p. 17, n. 8) apresenta uma vasta lista de autores, particularmente de época imperial, que fazem uso desta anedota sobre Demóstenes e a actio, postulando para ela uma fonte peripatética (Demétrio de Falero ou Teofrasto). Cícero a retomará em Brut. 146 e Or. 56.
} 
processo, os rodienses lhe pediram que lesse aquele célebre discurso que pronunciara contra Ctesifonte, tendo Demóstenes por adversário. Depois de terminada a leitura, pediram-lhe, no dia seguinte, que lesse também o discurso em defesa de Ctesifonte, que Demóstenes proferira em resposta. Depois de o ler com uma voz extremamente agradável e poderosa, diante da admiração geral, ele disse: "vocês ficariam ainda mais admirados, se tivessem ouvido o próprio Demóstenes!" Com isso mostrou bem quanto valor há na atuação, ao considerar que o mesmo discurso seria outro, com a mudança de orador. 214. O que havia em Graco - de quem você se lembra melhor que eu, Cátulo -, que era tão comentado ${ }^{8}$ quando eu era menino? "Para onde irei, pobre de mim? Para onde me voltarei? Para o Capitólio? Mas está banhado do sangue de meu irmão! Ou para casa? Para ver minha mãe se lamentando, aflita e prostrada?" Constava que proferira de tal forma essas palavras, com os olhos, com a voz, com os gestos, que mesmo seus inimigos não conseguiam conter as lágrimas. ${ }^{10}$ Detenho-me longamente sobre isso porque os oradores, que são os atores da própria realidade, abandonaram inteiramente esse tipo de coisa, enquanto os histriões, imitadores da realidade, se apossaram dele. ${ }^{11} 215$. Ora, não há

${ }^{7}$ Plínio, o Jovem, em Ep. 2.3, cita os termos que Ésquines supostamente teria usado: $\tau$ í

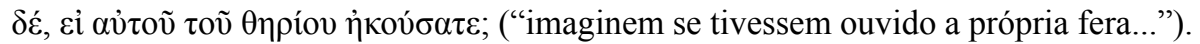
Referência em Russell (2001, p. 88, n. 5).

${ }^{8}$ Adota-se aqui a lição ferretur dos manuscritos, em lugar de efferretur, correção proposta por Lambino e aceita por Kumaniecki.

${ }^{9}$ Oratorum Romanorum Fragmenta fr. 23.61. Trata-se de fragmento do célebre discurso de Gaio Graco após o assassinato de seu irmão, Tibério Graco, em 133. A citação reelabora passo da Medeia de Ênio. Cf. 3.317, abaixo.

${ }^{10}$ Engenhosamente, a anedota introduz com vivacidade todos os tópicos fundamentais da atuação: o uso da expressão facial, da modulação de voz e da gesticulação por parte do orador; a demonstração de emoção por meio deles e a consequente incitação à emoção no público. Como bem observa Fantham (2004, p. 293-294): “[...] a maior diferença entre o tratamento da actio em Cícero e a discussão da pronuntiatio na Retórica a Herênio residirá na ênfase colocada por Crasso em demonstrar emoção não apenas pela voz, mas pelos olhos e pela expressão [...]."

${ }^{11}$ A comparação do orador com o ator é tradicional no contexto das discussões sobre a actio (o próprio Cícero já a fizera em 1.18: "Ora, para que me alongar sobre a própria atuação, que deve ser regulada pelo movimento corporal, pela gesticulação, pela expressão facial, pela inflexão e variação da voz? A importância que ela tem sozinha, 
dúvida de que em tudo a realidade supera a imitação. Porém, se por si mesma ela fosse tão eficaz na atuação, é evidente que não precisaríamos de arte. No entanto, como a paixão, que deve ser manifestada ou imitada sobretudo pela atuação, muitas vezes é tão confusa que chega a ficar obscurecida e quase eclipsada, é preciso eliminar os fatores que a tornam obscura e adotar os que são manifestos e visíveis. 216. De fato, toda emoção apresenta, por natureza, uma fisionomia, um som, um gesto que lhe são próprios, e todo o corpo do homem, bem como toda a sua fisionomia e todos os tons de voz ressoam, tal como as cordas da lira, da maneira como foram vibrados segundo cada emoção, ${ }^{12}$ pois os tons de voz, tal como as cordas, são retesados para corresponder a cada toque: agudo, grave, rápido, lento, alto, baixo. ${ }^{13}$ Contudo, entre cada um deles há um meio-termo em sua categoria. E há ainda numerosas categorias de tons que derivam dessas: suave, estridente, pacato, profuso, com ou sem pausa para respiração, entrecortado, brusco, elevado e diminuído pela variação de som. ${ }^{14}$ 217. Não há nenhuma dessas categorias que não seja tratada com arte e regra. Essas cores estão disponíveis para o orador, assim como para o pintor, com vistas à variação. É que um é o

por si mesma, é indicada pela insignificante arte dos atores e pelo palco, onde, apesar de todos esforçarem-se por controlar a fisionomia, a voz, os movimentos, quem ignora quão poucos há e houve a que suportemos assistir?"), apesar do baixo status social dos atores em Roma.

${ }^{12}$ Esta observação de Crasso é a chave para o entendimento da relação entre a atuação e o uso das emoções por parte do orador. De fato, se o orador quiser ser convincente, terá de demonstrar a emoção que quer incutir em seu ouvinte tanto pela voz como pelo gesto e pela expressão facial, e, como a cada emoção corresponde determinada voz, gesto ou expressão, o público perceberá se a atuação não lhes for correspondente. ${ }^{13}$ Variações de harmonia, ritmo e volume, respectivamente. A tríade fora delineada já por Aristóteles, no começo do livro 3 de sua Retórica (1403b): "A pronunciação assenta na voz, ou seja, na forma como é necessário empregá-la de acordo com cada emoção (por vezes forte, por vezes débil ou média) e como devem ser empregues os tons, ora agudos, ora graves ou médios, e também quais os ritmos de acordo com cada circunstância. São, por conseguinte, três os aspectos a observar: são eles volume, harmonia e ritmo" (Tradução de Alexandre Junior et al., 2005).

${ }^{14}$ Cf. Fantham (2011, p. 293). 
tom de voz que a cólera deve assumir, agudo, acelerado, repetidamente entrecortado: ${ }^{15}$

Meu próprio irmão me induz, em minha desgraça,

A devorar meus filhos. ${ }^{16}$

e aquele verso que você citou há pouco, Antônio:

Ousaste abandoná-lo...

e

Quem pagará por isso? Prendei-o! ${ }^{17}$

e quase todo o Atreu. Outro é o tom da compaixão e da tristeza, titubeante, carregado, entrecortado e com voz lamentosa: ${ }^{18}$

Para onde me voltarei agora? Que caminho passarei a trilhar?

Para a casa de meu pai? Ou para a das filhas de Pélia? ${ }^{19}$

e aquele:

Oh pai, oh pátria, oh morada de Príamo! ${ }^{20}$

${ }^{15}$ Cf. Cavarzere (2011, p. 69-75). Como observa Hall (2007, p. 222), a exposição da actio no De oratore muda o foco do tom de voz adequado a cada parte do discurso, como se encontra na Retórica a Herênio, para uma apresentação segundo o tipo de emoção a ser demonstrada e transmitida pelo orador.

${ }^{16}$ Fragmento do Atreu de Ácio (v. 196-197 Remains of Old Latin). As ambiguidades e divergências de leitura propiciadas pelas citações poéticas causam estupefação ao leitor moderno. Fantham (2004, p. 295) apresenta uma explicação plausível (pace CAVARZERE, 2011, p. 65): mais que ler, o público contemporâneo de Cícero ouviria os versos citados, interpretados por um lente, que se serviria da caracterização inicial do tom de voz adequado a cada emoção, como uma espécie de partitura.

${ }^{17}$ Fragmento do Atreu de Ácio (v. 198 Remains of Old Latin).

${ }^{18}$ Cf. Cavarzere (2011, p. 75-77).

${ }^{19}$ Fragmento da Medeia de Ênio (v. 284-285 Remains of Old Latin).

${ }^{20}$ Fragmento da Andrômaca de Ênio (v. 101 Remains of Old Latin). 
e os seguintes:

Vi tudo isso em chamas,

Vi a vida ser arrancada de Príamo. ${ }^{21}$

218. Outro é o tom do medo, baixo, hesitante e abatido: ${ }^{22}$

Estou cercado por toda parte: pela doença, pelo exílio e pela pobreza, então o pavor arranca-me do peito ofegante toda a sabedoria; minha mãe ameaça minha vida com terrível suplício e com a morte, e ninguém é dotado de natureza tão segura e de tamanha confiança que não fuja do sangue por receio e que não fique pálido de medo. ${ }^{23}$

219. Outro, o da impetuosidade, intenso, enérgico, ameaçador, de uma exaltação grave: ${ }^{24}$

Novamente Tiestes aproxima-se para agredir Atreu,

Novamente me ataca e perturba-me o repouso.

Devo provocar uma desgraça maior, um mal maior,

Para esmagar e oprimir seu coração acerbo. ${ }^{25}$

Outro, o do regozijo, expansivo e terno, alegre e calmo: ${ }^{26}$

Mas quando trouxe a coroa, pela união nupcial, Ela a trouxe para ti; quando simulava pegar a tocha para si, Brincando, fina e delicada, entregou-a para ti. ${ }^{27}$

\footnotetext{
${ }^{21}$ Fragmento da Andrômaca de Ênio (v. 106-107 Remains of Old Latin).

${ }^{22}$ Cf. Cavarzere (2011, p. 77-78).

${ }^{23}$ Fragmento do Alcmeão de Ênio (v. 25-29 Remains of Old Latin).

${ }^{24}$ Cf. Cavarzere (2011, p. 78-80).

${ }^{25}$ Fragmento do Atreu de Ácio (v. 163-166 Remains of Old Latin).

${ }^{26}$ Cf. Cavarzere (2011, p. 80-81).

${ }^{27}$ Citação de origem incerta.
} 
Outro, o da aflição, grave, de certa forma, mas sem lamentação, e abafado numa única articulação e tom..$^{28}$

Na época em que Páris uniu-se a Helena em núpcias inuptas, Eu estava grávida, passados já quase todos os meses para o parto; Por aquele tempo, Hécuba deu à luz Polidoro, em seu parto derradeiro. ${ }^{29}$

220. Todas essas emoções devem ser acompanhadas por gestos, embora não os do teatro, que traduzem as palavras, mas que exprimam o conteúdo e o pensamento como um todo não por mímica, mas por sugestão, com esta postura enérgica e viril do corpo, proveniente, não do teatro e dos histriões, mas do exército ou mesmo da palestra. A mão não muito expressiva, que siga, não exprima, as palavras com os dedos; o braço projetado com toda a rapidez, como uma espécie de lança do discurso; a batida do pé no começo ou no fim dos embates. 221. Mas o mais importante encontra-se no rosto: é exatamente nele que reside todo o poder dos olhos. Por isso agiram com mais acerto aqueles nossos velhos conterrâneos, que não elogiavam muito nem mesmo Róscio, quando usava a máscara ${ }^{30}$ De fato, toda a atuação concerne à alma, e o retrato da alma é o rosto; seus mensageiros, os olhos. É que esta é a única parte do corpo que é capaz de traduzir tantas indicações e mudanças das emoções quantas existem, e a verdade é que não há ninguém que possa fazer o mesmo de olhos fechados. Realmente, Teofrasto afirma que certo Taurisco costumava dizer que o orador que, ao discursar, exprimia-se olhando fixamente para algum ponto, discursava de costas para o público. ${ }^{31}$ Daí a importância do controle sobre os olhos. 222. De

\footnotetext{
${ }^{28}$ Cf. Cavarzere (2011, p. 81).

${ }^{29}$ Fragmento da Iliona de Pacúvio (v. 215-217 Remains of Old Latin).

${ }^{30}$ Fantham (2011, p. 289) considera que a explicação mais plausível para esta observação de Crasso é que as máscaras teriam sido introduzidas no teatro de Roma na geração anterior à da data dramática da obra.

${ }^{31}$ Teophr. fr. 713 FHS\&G. Citação de origem incerta, podendo remeter tanto ao Пєрi vं (Cf. CAVARZERE, 2011, p. 28, com referências na nota 47). Para interpretações e
} 
fato, não se deve mudar excessivamente o aspecto do rosto, para não incorrermos em impertinências ou em algum esgar. É pelos olhos que devemos manifestar as emoções, ora com o olhar fixo, ora relaxado, ora atento, ora alegre, de maneira adequada ao próprio tom do discurso. De fato, a atuação é como que a linguagem do corpo, ${ }^{32}$ uma razão a mais para que deva estar em harmonia com a mente. A natureza nos deu os olhos para manifestarmos nossas emoções, tal como deu as crinas, a cauda e as orelhas para o cavalo ou o leão. 223. Por isso, nesta nossa atuação, depois da voz, predomina a fisionomia. Ela, por sua vez, é governada pelos olhos. Ademais, em tudo o que concerne à atuação, existe uma espécie de força conferida pela natureza. É por isso que mesmo os leigos, o vulgo, os bárbaros, em suma, comovem-se particularmente com ela. De fato, as palavras movem apenas quem esteja ligado pela comunhão da mesma língua, e muitas vezes pensamentos finos passam despercebidos aos sentidos de pessoas sem fineza. A atuação, que expressa a emoção, move a todos, pois os ânimos de todas as pessoas são incitados pelas mesmas emoções, e elas as reconhecem pelos mesmos sinais também nos outros e as demonstram em si mesmas.

224. Mas, para a efetividade e a excelência da atuação, sem dúvida a voz desempenha o papel mais importante. É preciso, em primeiro lugar, desejar ter uma boa voz; em seguida, qualquer que ela seja, preservá-la. Nesse sentido, a maneira de cuidarmos da voz não tem relação alguma com esse tipo de preceituação. De minha parte, no entanto, considero que devemos cuidar muito dela. Ora, não parece estar muito distante do propósito desta nossa conversa o fato de, como disse há pouco, aquilo que é mais útil na maior parte dos casos ser também, não sei por que motivo, o mais decoroso. De fato, para preservar a voz, nada é mais útil do que uma variação constante, nada mais danoso do que forçá-la excessivamente e sem interrupção. ${ }^{33} 225$. Ora, o que é mais adequado aos

traduções alternativas da citação, cf. Fortenbaugh (2005, p. 409-415). Nada se sabe sobre o Taurisco em questão.

${ }^{32}$ Ideia retomada por Cícero em Or. 55: "De fato, a atuação é uma espécie de eloquência do corpo, por assim dizer, sendo constituída de voz e movimento.”

${ }^{33} \mathrm{Na}$ seção autobiográfica do Bruto, Cícero relata que, em seus primeiros anos como orador, sofria por seu uso excessivo da voz, tendo sido mesmo aconselhado por amigos 
nossos ouvidos e ao encanto da atuação do que a alternância, a variedade e a mudança? Assim, o mesmo Graco - como você, Cátulo, pode ouvir de Licínio, seu cliente, homem culto, um escravo que Graco tinha como secretário - quando discursava perante o povo, costumava manter oculto, atrás de si, um perito com uma flauta de marfim, que tocava rapidamente a nota para estimulá-lo, quando falava muito calmamente, ou controlá-lo, quando forçava a voz.

- Ouvi sim - respondeu Cátulo -, e muitas vezes admirei não apenas o zelo desse homem, mas também sua formação e seu conhecimento.

226. - Na verdade - observou Crasso -, chego a lamentar que aqueles homens tenham incorrido em tal erro, no campo da política - embora se teça tal trama, promova-se e mostre-se à posteridade tal modo de vida nesta cidade, que já começamos a desejar ter concidadãos semelhantes àqueles que nossos antepassados não conseguiram tolerar.

- Deixe esse assunto de lado, Crasso - disse Júlio -, e torne à flauta de Graco, cuja motivação ainda não compreendo claramente.

227. - Em todo tipo de voz - continuou Crasso -, há uma espécie de meio-termo, mas cada um tem o seu. Elevar a voz gradualmente a partir dele é útil e agradável - pois bradar desde o princípio é algo grosseiro - e, ao mesmo tempo, salutar para dar firmeza à voz. Em seguida há uma espécie de ponto máximo de elevação, ainda que mais baixo do que um grito extremamente agudo, a que a flauta não o deixará chegar, afastando-o, contudo, da própria elevação. Em contrapartida, há igualmente um extremo mais grave na voz baixa, e com ele como que se desce por graus de tom. Essa variedade e essa passagem por todos os tons de voz não só servirão para protegê-la, como também conferirão encanto à atuação. E vocês deixarão o flautista em casa, levando consigo para o fórum o sentido dessa prática.

228. Apresentei o que pude, não de acordo com minha vontade, mas conforme me obrigaram as limitações de tempo. É elegante atribuir

e médicos a deixar de discursar para não colocar sua saúde em risco. Tal defeito teria sido corrigido em sua viagem de aprendizado em Atenas, em Rodes e na Ásia Menor, entre 79 e 77. Cf. Brut. 313-316. 
a causa ao tempo quando não se é capaz de acrescentar mais nada, ainda que se queira.

- Na verdade - observou Cátulo -, até onde posso julgar, você reuniu todos os elementos de uma maneira tão divina, ${ }^{34}$ que não parece que os tomou aos gregos, mas que é capaz de ensiná-los a eles próprios. ${ }^{35}$ Alegro-me de ter sido aceito para participar desta conversa, e gostaria que meu genro, Hortênsio, seu colega, tivesse estado presente: confio que ele se sobressairá em todos esses méritos que abarcou em sua fala.

229. E Crasso disse:

- Você diz “se sobressairá"? Na verdade, julgo que já se sobressai, e já o julgava quando defendeu a causa da África no Senado, em meu consulado, ${ }^{36}$ e mais ainda há pouco tempo, quando defendeu o rei da Bitínia. Por isso, sua percepção é correta, Cátulo: penso que nada falta a esse jovem no que concerne à natureza ou à formação teórica. ${ }^{37} 230$. Eis por que você, Cota, e você, Sulpício, devem atentar e trabalhar mais. De fato, não é um orador qualquer que está despontando, por assim dizer, para suceder a geração de vocês, mas alguém dotado de um engenho

${ }^{34}$ Para uma interpretação do léxico do divino no De oratore e sua aplicação às personagens da obra, leia-se o excelente artigo de Stull (2011).

${ }^{35}$ Esta observação de Cátulo, já quase no fim do diálogo, espelha e confirma o que dissera Cícero no começo da obra, ao fim do prólogo do primeiro livro (1.23): "Não é que eu despreze o que os mestres e professores de oratória gregos nos legaram, mas, como tais escritos são acessíveis e estão ao alcance de todos, não podendo, por meio de minha tradução, ser explicados com maior ornato ou expressos com maior clareza, acredito que me concederás a licença, meu irmão, de colocar acima dos gregos a autoridade daqueles a quem nossos conterrâneos concederam a suprema excelência na oratória" (Grifo nosso).

${ }^{36} \mathrm{Em} 95$.

${ }^{37} \mathrm{O}$ elogio de Hortênsio, fechando a obra, imita o final do Fedro de Platão (279a), que se encerra com o elogio de Isócrates: "[sc. Isócrates] parece-me ser muito superior em dotes naturais para se fazer uma comparação com a eloquência de Lísias e, além disso, temperado por um carácter mais nobre. Desse modo, não seria para admirar se, no que respeita ao género oratório a que agora se dedica, com o avanço da idade, viesse a distinguir-se mais do que outros jovens que actualmente se entregam à eloquência; e, caso isso não lhe fosse ainda suficiente, se um impulso mais sublime, divino o levasse para obras mais elevadas. É que, meu caro amigo, no espírito desse homem há um desejo inato de saber" (Tradução de Ferreira, 2009). 
extremamente penetrante, uma dedicação ardente, exímia formação teórica e uma memória singular. Embora o queira bem, desejo que ele seja superior à sua própria geração, mas é quase desonroso que, sendo tão mais jovem, leve vantagem sobre vocês. Mas agora vamos nos levantar - disse -, nos reconfortar e, enfim, aliviar nossos ânimos e nossa mente da tensão deste debate. ${ }^{38}$

\section{Referências}

ALEXANDRE JUNIOR, M.; ALBERTO, P. F.; PENA, A. N. (trad.). Aristóteles: Retórica. Lisboa: Imprensa Nacional-Casa da Moeda, 2005.

CAVARZERE, A. Gli Arcani dell'oratore: Alcuni appunti sull'actio dei Romani. Roma: Padova: Editrice Antenore, 2011.

FANTHAM, E. Orator and/et actor. In: . Roman Readings. Göttingen: De Gruyter, 2011. p. 285-301. DOI: https://doi. org/10.1515/9783110229349.

FANTHAM, E. The Roman World of Cicero's De oratore. Oxford: Oxford University Press, 2004. DOI: https://doi.org/10.1093/ acprof:oso/9780199263158.001.0001.

FERREIRA, J. R. (trad.). Platão: Fedro. Lisboa: Edições 70, 2009.

FORTENBAUGH, W. W. (ed.). Theophrastus of Eresus Commentary Volume 8: Sources on Rhetoric and Poetics (Texts 666-713). Leiden: Boston: Brill, 2005. DOI: https://doi.org/10.1163/9789047415190.

HALL, J. Oratorical Delivery and the Emotions: Theory and Practice. In: DOMINIK, W.; HALL, J. (ed.). A Companion to Roman Rhetoric. Oxford: Blackwell, 2007. p. 218-234. DOI: https://doi. org/10.1002/9780470996485.ch17

\footnotetext{
${ }^{38} \mathrm{O}$ diálogo começa e termina com a ideia de relaxamento proposta por Crasso. Cf. 1.29: "Cota costumava contar que naquele momento, para que as mentes de todos pudessem relaxar da conversa precedente, Crasso iniciara uma conversa acerca do estudo da oratória." A ironia reside no fato de que, em 1.29, o relaxamento consistirá em deixar de lado os assuntos políticos e conversar sobre oratória; aqui em 3.230, último parágrafo da obra, o relaxamento consistirá em deixar de lado... a conversa sobre oratória!
} 
MALCOVATI, E. (ed.) Oratorum Romanorum Fragmenta. 4. ed. Torino: Paravia, 1976.

RUSSELL, D. A. (trad.). Quintilian: The Orator's Education, Books 1112. Cambridge, Mass.; Londres: Harvard University Press, 2001.

SCATOLIN, A. Cícero, Do orador 1.122-159. Nuntius Antiquus, Belo Horizonte, v. 12, n. 2, p. 264-287, 2016. DOI: https://doi. org/10.17851/1983-3636.12.2.264-287.

STULL, W. Deus ille noster: Platonic Precedent and the Construction of the Interlocutors in Cicero's De oratore. Transactions of the American Philological Association, Baltimore, v. 141, n. 2, p. 247-263, 2011. DOI: https://doi.org/10.1353/apa.2011.0015.

WARMINGTON, E. H. (ed.). Remains of Old Latin. Cambridge, Mass.; Londres: Harvard University Press, 1936.

WISSE, J.; WINTERBOTTOM, M.; FANTHAM, E. M. Tullius Cicero - De oratore libri III: A Commentary on Book III, 96-230. Heidelberg: Universitätsverlag Winter, 2008.

Recebido em: 6 de setembro de 2019. Aprovado em: 28 de novembro de 2019. 